OPEN ACCESS

Edited by:

David Gonzalez-Gomez,

University of Extremadura, Spain

Reviewed by:

Michael Loui,

University of Illinois

at Urbana-Champaign, United States

Vicente Alfonso-Benlliure,

University of Valencia, Spain

${ }^{*}$ Correspondence:

Yubin Wu

xiaowu7a@sina.com

Specialty section:

This article was submitted to

Educational Psychology,

a section of the journal

Frontiers in Psychology

Received: 27 August 2021

Accepted: 19 October 2021

Published: 16 November 2021

Citation:

Wu Y, Wu Y, Chong D and

Zhang W (2021) The Promotion of Creativity of Vocational College Students: The Role of Parent-Child Relationship, Emotional Intelligence, and Grit. Front. Psychol. 12:765444.

doi: 10.3389/fpsyg.2021.765444

\section{The Promotion of Creativity of Vocational College Students: The Role of Parent-Child Relationship, Emotional Intelligence, and Grit}

\author{
Yushen $W u^{1}$, Yubin $W u^{2 *}$, Daohan Chong ${ }^{3}$ and Wen Zhang ${ }^{1}$ \\ ' Faculty of Psychology, Beijing Normal University, Beijing, China, ${ }^{2}$ Hakka Studies College of Gannan Normal University, \\ School of History Culture and Tourism, Gannan Normal University, Ganzhou, China, ${ }^{3}$ Shandong Water Conservancy \\ Vocational College, Rizhao, China
}

Objective: To examine whether emotional intelligence played a mediation role in the association between parent-child relationship and vocational college student's creativity, and whether grit moderated this mediating process.

Methods: 663 vocational college students participated in this study and completed four questionnaires at three time points, which included measures of parent-child relationship, creativity, emotional intelligence, and grit.

Results: (1) Emotional intelligence mediated the relationship between parent-child relationship and vocational college student's creativity; (2) grit moderated the mediating role of emotional intelligence between parent-child relationship and vocational college student's creativity.

Conclusion: Parent-child relationship had both direct effects on vocational college student's creativity and indirect effects through emotional intelligence. Grit moderates the effect of emotional intelligence on vocational college student's creativity.

Keywords: parent-child relationship, creativity, emotional intelligence, grit, vocational college student

\section{INTRODUCTION}

In recent years, technological innovation is an important engine for national development. To cultivate innovation, it is important to improve individual creativity, because creativity can help promote the adjustment of the country's economic structure and continuously enhance the new impetus for economic development. Expansion of higher education has become commonplace in developed economies as a well-educated and highly skilled population, as human intellectual capital, is considered a core aspiration to securing economic advantage in the global knowledge market (Parry, 2009; Gale and Tranter, 2011; Griffioen and de Jong, 2013; Avis and Orr, 2016). Creativity is an important indicator for the cultivation of innovative talents in colleges and universities, especially for vocational college students. The future career of vocational college students is mainly based on technology, and the cultivation of their innovation is an important part of the country's innovative talent reserve (Xue and Li, 2021). Therefore, in the era of advocating innovation, it is necessary to explore the mechanisms that relate to individual creativity in order to effectively develop individual creativity and enhance the creative ability of vocational college students. Based on the person-environment fit theories of creativity, this research explores the 
impact of parent-child relationship as environmental factors, emotional intelligence, and grit as individual factors on creativity of vocational college students.

Creativity is not determined solely by personality traits, thinking habits, or abilities, and the environment in which the individual is located, and it is determined by the interaction of various factors, such as researchers believe that creativity comes from the interaction of individuals, fields, and domains (Csikszentmihalyi, 1999). Runco (2007) emphasizes the important impact of the interaction between human and environment on innovation performance. Therefore, it is particularly important to understand creativity from the person-environment fit theories, the theory believes that the interaction between the individual and the environment is the essential element that affects individual creativity (Sen et al., 2014). So this study evaluates creativity from both personal and environmental aspects. Parent-child relationship is an important environmental factor affecting individual development, research has shown that an important factor affecting the development of individual creativity is the parent-child relationship (Li and Shi, 2004). A good and harmonious parent-child relationship plays an important role in the individual's psychological and behavioral development (An and Cooney, 2006; Brook et al., 2006). Being in a close and harmonious parent-child relationship for a long time will provide more possibilities for the development of individual creativity, studies have shown that early family environment, such as parent-child relationship, is related to higher level of individual creativity (Zhang D. et al., 2018). Attachment theory points out that a good parentchild relationship is a protective factor for the development of individual behavior and various abilities (creativity) (Bowlby, 2010; Padilla-Walker et al., 2016). Although the relationship between parent-child relationship and creativity is relatively clear, the internal mechanism of action remains unclear.

Ecosystem theory points out that individual characteristics and environmental factors have important impacts on individual development (Bronfenbrenner, 1989). Emotional intelligence refers to an individual's ability to perceive, express, and manage his or her own emotions, and to recognize others' emotions, and to use the information to guide his or her thinking and actions (Joseph and Newman, 2010). It is also an individual's ability to manage emotions and communicate with others in life (Joseph and Newman, 2010). Attachment internal working model indicates that parent-child relationship can affect the individual's perception, that perception by providing their own emotions, understand the emotions of others, manage their emotions, assessing emotions of others pattern and thus enhance the emotion regulation and social adaptability of individuals (Bowlby, 2010). The empirical results also confirmed that good parent-child relationship will significantly enhance emotional intelligence (Bruce, 2014; Wang et al., 2019). On the other hand, individual's emotional intelligence will also affect the development of creativity, the higher the level of emotional intelligence, the stronger their creativity (Rodrigues et al., 2019). Emotional information processing theory also pointed out that, for each processing needs, individuals with high emotional intelligence are accustomed to using effective emotional management strategy while maintaining individual positive emotions, thus enhancing their creativity fundamentally (Côté, 2014). Brackett et al. (2011) also pointed out the individual with high emotional intelligence will respond effectively to the everyday environment and to take creatively. It can be inferred from this that the parent-child relationship may affect the development of creativity by affecting the development of individual emotional intelligence. Therefore, this study proposes the hypothesis that the emotional intelligence of vocational college students plays a mediating role in the influence of parent-child relationship on individual creativity.

Mediating variables have a clear explanation of "commonness and process," but the question "personality or conditions" between independent variables and the outcome variable lacks of attention. In this study, emotional intelligence can explain the "process" between parent-child relationship and creativity, but it cannot explain whether there are other variables moderating this "process."

The individual environment interaction model points out that individuals who grow up in different environments may show different behaviors or problems even if they have the same characteristics and abilities (Neufeld et al., 2006). Grit is a positive psychological quality, which shows perseverance of effort and consistency of interest. Study found that the quality of grit is important for the healthy growth of the individual (Duckworth et al., 2007). Resilience protection model theory points out that protective factors can effectively alleviate the negative impact of risk factors on their development, and promote the healthy development of individual (Garmezy et al., 1984). Grit, as a protective psychological quality, may also play the same role, and individuals with high level of grit may try their best to overcome difficulties in the process of achieving long-term goals, especially in challenging and creative work or tasks. The empirical study also found that grit can effectively alleviate the negative effects of negative events on individual adaptation and learning, and enhance positive energy (O'Neal et al., 2016; Lei et al., 2019). In addition, because emotional intelligence and grit are closely related to parent-child relationship, and largely depend on the quality of parent-child relationship to form and develop. Therefore, this study proposes the hypothesis that grit only plays a moderating role in the path of emotional intelligence and creativity.

In conclusion, based on the person-environment fit theories of creativity, this study constructs a moderated mediating model. The main purpose of this study is to explore the mechanism of parent-child relationship affecting individual creativity, to examine whether emotional intelligence mediates this relationship, and whether grit moderates the influence of emotional intelligence on individual creativity. Based on the above theory and hypothesis of this study, a theoretical model of the mechanism effect of vocational college students' parent-child relationship on creativity was constructed in Figure 1. 


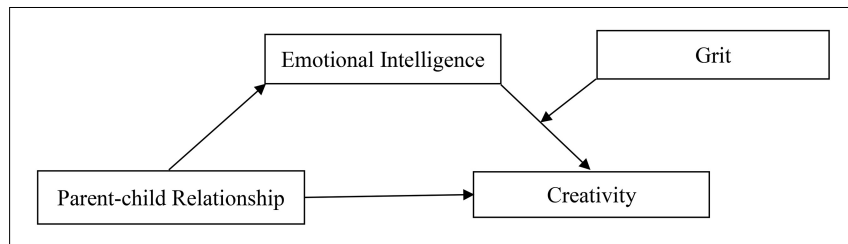

FIGURE 1 | The mechanism effect of vocational college students' parent-child relationship on creativity.

\section{MATERIALS AND METHODS}

\section{Participants and Procedure}

This study randomly selected three vocational colleges in Shandong Province, China, and the survey process was approved by the principal of three vocational colleges. 680 students were randomly selected from these three colleges according to their student id numbers. In order to avoid common method bias, sample data were collected at three time points, and the time interval was 2 months. Parent-child relationship was measured at time point 1 , emotional intelligence and grit were measured about 2 months later (time point 2), and creativity was measured about 2 months later (time point 3). We conducted a questionnaire survey with the teacher's consent before the students started the class, it was done as an assignment for the students, so we recovered 680 questionnaires, the recovery rate is $100 \%$. And we conducted on-site guidance to students throughout the investigation process. However, 17 questionnaires were incompletely filled, and some items were not filled in by the subjects, which were excluded by us, so we obtained 663 valid questionnaires with a questionnaire efficiency of $97.5 \%$. Among them, there are 134 men and 529 women, with an average age of 19.71 years and a standard deviation of 0.97 . Sensitivity analysis using G*Power (Faul et al., 2009) revealed that, a study with this sample size can detect medium sized effect in an independent samples $t$-test $(\alpha=0.05$, two-tailed): effect sizes $=0.55$, with sufficient power $(1-\beta>0.95)$.

\section{Measures}

\section{Parent-Child Relationship}

The family adaptation and parent-child affinity evaluation scale revised (Olson et al., 1979) by Zhang et al. (2006) was used to measure the parent-child relationship of vocational college students. The scale has an affinity with the father-child affinity and mother affinity two dimensions, comprising 20 items, Likert 5 -point score $(1=$ almost never, almost always $=5)$, The higher the score of the scale, the better the quality of the parent-child relationship of the research subject. This scale was reliable in this study (Cronbach's $\alpha=0.897$ ), and the confirmatory factor analysis result was $\chi^{2} / d f=3.274, C F I=0.969, C F I=0.940$, RMSEA $=0.059, p<0.001$, which showed that the scale had a good structural validity.

\section{Creativity}

The person-environment fit scale of creativity (PEFSC) compiled by Sen et al. (2014) was used to measure the creativity of vocational college students. The scale contains two factors: individual and environment. Each factor contains 7 items, and each item uses Likert's 5 -point scoring ( $1=$ none, $5=$ always $)$. The higher the scale score, the higher the individual's creativity level. This scale was reliable in this study (Cronbach's $\alpha=0.96$ ), and the confirmatory factor analysis result was $\chi^{2} / d f=3.419$, $C F I=0.980, G F I=0.955, R M S E A=0.060, p<0.001$, which showed that the scale had a good structural validity.

\section{Emotional Intelligence}

The Emotional Intelligence Scale compiled by Hong Kong scholar Wong and Law (2002) was used to measure the emotional intelligence of vocational college students. The scale contains 16 items, divided into four dimensions: self-emotion assessment, other people's emotion assessment, emotion management and emotion utilization. Each project uses Likert's 7-point scoring $(1=$ completely disagree, $7=$ completely agree $)$. The higher the scale score, the higher the individual's emotional intelligence level. This scale was reliable in this study (Cronbach's $\alpha=0.95$ ), and the confirmatory factor analysis result was $\chi^{2} / d f=2.589$, $C F I=0.985, G F I=0.958, R M S E A=0.049, p<0.001$, which showed that the scale had a good structural validity.

\section{Grit}

The Grit Scale compiled by Duckworth et al. (2007) was used to measure the grit of vocational college students. The questionnaire contains two dimensions: consistency of interest and persistence of effort, a total of 12 items, using Likert 5-point scoring $(1=$ very unlike me, $5=$ completely like me). The higher the scale score, the higher the individual's grit level. This scale was reliable in this study (Cronbach's $\alpha=0.87$ ), and the confirmatory factor analysis result was $\chi^{2} / d f=3.210, C F I=0.981, G F I=0.971$, RMSEA $=0.058, p<0.001$, which showed that the scale had a good structural validity.

\section{Data Analysis}

The SPSS 22.0 statistical software was used for descriptive statistics, correlation analysis, and moderated mediating model analysis, and adopted the Bootstrap program for inspection. And AMOS 22.0 was used for confirmatory factor analysis.

\section{RESULTS}

\section{Common Method Deviation Analysis}

The study adopted Haman's single-factor test to carry out the common method deviation analysis on all the valid data (Podsakoff et al., 2003). As a result, the present study found that there were 11 factors featuring root values greater than one and that the variance of the first one was $32.35 \%$, smaller than the critical value of $40 \%$, which meant that the common deviation method of the study was not remarkable.

\section{Preliminary Analysis}

The results of descriptive statistics and correlation analysis are shown in Table 1. Results revealed that vocational college students' parent-child relationship had a positive correlation with 
TABLE 1 | Correlation coefficients, means, and standard deviations of variables $(n=663)$.

\begin{tabular}{|c|c|c|c|c|c|c|}
\hline & $M \pm S D$ & 1 & 2 & 3 & 4 & 5 \\
\hline (1) Gender & - & - & & & & \\
\hline (2) Age & $19.71 \pm 0.97$ & 0.22 & - & & & \\
\hline (3) Parent-child relationship & $3.72 \pm 0.61$ & -0.08 & -0.07 & - & & \\
\hline (4) Emotional intelligence & $5.10 \pm 0.96$ & $0.11^{* \star}$ & 0.08 & $0.37^{\star \star}$ & - & \\
\hline (5) Grit & $3.14 \pm 0.38$ & 0.07 & -0.03 & $0.30^{\star \star}$ & $0.38^{\star \star}$ & - \\
\hline (6) Creativity & $3.54 \pm 0.72$ & $0.13^{\star \star}$ & $-0.11^{\star \star}$ & $0.36^{\star \star}$ & $0.57^{\star \star}$ & $0.33^{\star \star}$ \\
\hline
\end{tabular}

creativity $(r=0.36, p<0.01)$, emotional intelligence $(r=0.37$, $p<0.01)$, and grit $(r=0.30, p<0.01)$. Emotional intelligence had a positive correlation with creativity $(r=0.57, p<0.01)$ and grit $(r=0.38, p<0.01)$. Grit had a positive correlation with creativity $(r=0.33, p<0.01)$. It was show that it was necessary to further reveal the internal relationship between the elements.

\section{Moderated Mediation Model Testing}

Although the moderated effect of grit on emotional intelligence and individual creativity was theoretically described, in order to verify the overall effect of grit, the moderated effect of grit on three pathways of the mediating model was verified separately. According to Wen and Baojuan (2014), three regression equations were tested in this study. Equation 1 tested the moderated effect of grit on parent-child relationship and individual creativity. Equation 2 tested the moderated effect of grit on parent-child relationship and emotional intelligence. Equation 3 tested the moderated effect of grit on emotional intelligence and individual creativity. All predictive variables were normalized in each equation (Garmezy et al., 1984). In addition, previous studies have shown that gender, age are important factors that influence volunteering behavior (Warren et al., 2018; Zhang W. J. et al., 2018), therefore, the present study viewed gender and age were used as control variables.

During the analysis, we found that the variance inflation factor (VIF) of all the predictive variables was less than 10 . Therefore, there was no serious multicollinearity problem in this study. As shown in Table 2, parent-child relationship in Equation 1 was positively correlated with individual creativity, and the interaction term of parent-child relationship and grit was not significantly correlated with individual creativity (grit $\times$ parent-child relationship). In Equation 2, parentchild relationship was positively correlated with emotional intelligence, and the interaction term of parent-child relationship and grit was not significantly correlated with emotional intelligence (grit $\times$ parent-child relationship). In Equation 3, emotional intelligence was positively correlated with individual creativity, and the interaction term of emotional intelligence and grit was significantly correlated with individual creativity (grit $\times$ emotional intelligence). In conclusion, we could conclude that emotional intelligence played a mediating role between parent-child relationship and individual creativity, and the mediating effect accounted for $30.54 \%$ of the total effect. In order to further tested whether there was a mediating effect, carried out the bootstrap inspection of the $95 \%$ confidence interval, if the
95\% confidence interval does not contain 0 , the mediating effect was significant (Preacher and Hayes, 2004; Preacher et al., 2007). We carried out the bootstrap inspection of the $95 \%$ confidence interval, setting the self-sampling number to 5,000, and the $95 \%$ confidence interval was $[0.165,0.286]$, which did not contain 0 , therefore, it was indicated that the mediating effect of emotional intelligence exists. In addition, the study also found that grit only moderated the relationship between emotional intelligence and individual creativity, that is, it moderated the latter half of the mediating model.

In order to further explore how grit regulates the relationship between emotional intelligence and individual creativity, a simple slope analysis was conducted. According to the standard of one standard deviation above (below) the mean, the groups with high and low grit levels were divided into two groups. The results showed that with the increase of emotional intelligence, the creativity of both high grit $\left(B_{\text {simple slope }}=-0.24, t=-5.73\right.$, $p<0.001)$ and low grit $\left(B_{\text {simple slope }}=-0.45, t=-10.34\right.$, $p<0.001)$ groups increased significantly, but the creativity of high grit group increased more obviously (see Figure 2).

\section{DISCUSSION}

This study builds a moderated mediation model to test the relations of grit and emotional intelligence and parent-child relationship and individual creativity. The study found that emotional intelligence acted as a mediation between the parentchild relationship and individual creativity, in addition, the second half path of the mediation was moderated by grit after controlling gender and age.

\section{The Mediating Effects of Emotional Intelligence}

This study not only verifies that the parent-child relationship has a direct impact on individual creativity, but also finds that emotional intelligence plays in part a mediating role in individual creativity, which indicates that the parent-child relationship not only has a direct bearing on individual creativity, but also has an indirect effect on individual creativity by cultivating individuals' emotional intelligence.

This study can explain the mediating effects of emotional intelligence from the following aspects. First, emotional intelligence in theoretical terms is the capability of individuals to recognize their own emotions and those of others, discern between different feelings and label them appropriately, use emotional information to guide thinking and behavior, and adjust emotions to adapt to environments (Joseph and Newman, 2010). The broaden-and-build theory of positive emotions suggests that positive emotions broaden one's awareness and encourage novel, varied, and exploratory thoughts and actions (Fredrickson, 2001). In other words, positive emotions can effectively help individuals develop divergent thinking and develop more novel designs (plans) (Duan et al., 2013). Affective events theory (AET) also suggests that positive emotions can effectively improve individuals' divergent thinking and further develop more novel designs (plans) in their work or study 
TABLE 2 | Moderated mediation model analysis $(n=663)$.

\begin{tabular}{|c|c|c|c|c|c|c|c|c|c|}
\hline & \multicolumn{3}{|c|}{$\begin{array}{l}\text { Equation 1(outcome } \\
\text { variable: creativity) }\end{array}$} & \multicolumn{3}{|c|}{$\begin{array}{l}\text { Equation 2(outcome variable: } \\
\text { emotional intelligence) }\end{array}$} & \multicolumn{3}{|c|}{$\begin{array}{l}\text { Equation } 3 \text { (outcome } \\
\text { variable: creativity) }\end{array}$} \\
\hline & $\beta$ & $t$ & $95 \% \mathrm{Cl}$ & $\beta$ & $t$ & $95 \% \mathrm{Cl}$ & $\beta$ & $t$ & $95 \% \mathrm{Cl}$ \\
\hline Gender & 0.24 & $3.87^{\star \star \star}$ & {$[0.12,0.37]$} & 0.26 & $3.14^{\star \star}$ & {$[0.10,0.42]$} & 0.15 & $2.58^{\star}$ & {$[0.04,0.26]$} \\
\hline Age & -0.03 & $-0.34^{\star}$ & {$[-0.06,-0.01]$} & 0.02 & 1.03 & {$[-0.02,0.06]$} & -0.04 & $-3.23^{\star \star}$ & {$[-0.07,-0.02]$} \\
\hline Parent-child relationship & 0.36 & $8.24^{\star \star \star}$ & {$[0.27,0.45]$} & 0.46 & $8.14^{\star \star \star}$ & {$[0.35,0.58]$} & 0.19 & $4.66^{\star \star \star}$ & {$[0.11,0.27]$} \\
\hline Emotional intelligence & & & & & & & 0.36 & $13.59^{\star \star \star}$ & {$[0.31,0.42]$} \\
\hline Grit & 0.42 & $5.98^{\star \star \star}$ & {$[0.28,0.56]$} & 0.72 & $7.85^{\star \star \star}$ & {$[0.54,0.90]$} & 0.14 & $2.16^{\star}$ & {$[0.01,0.27]$} \\
\hline Grit $\times$ parent-child relationship & 0.03 & 1.45 & {$[-0.01,0.08]$} & 0.01 & 0.16 & {$[-0.05,0.06]$} & & & \\
\hline Grit $\times$ emotional intelligence & & & & & & & 0.05 & $2.59^{\star}$ & {$[0.01,0.08]$} \\
\hline$R^{2}$ & \multicolumn{3}{|c|}{0.21} & \multicolumn{3}{|c|}{0.23} & \multicolumn{3}{|c|}{0.38} \\
\hline$F$ & \multicolumn{3}{|c|}{$33.20^{\star \star \star}$} & \multicolumn{3}{|c|}{$39.30^{\star \star \star}$} & \multicolumn{3}{|c|}{$67.85^{\star \star \star}$} \\
\hline
\end{tabular}

${ }^{*} p<0.05,{ }^{* *} p<0.01$, and ${ }^{* *} p<0.001$.

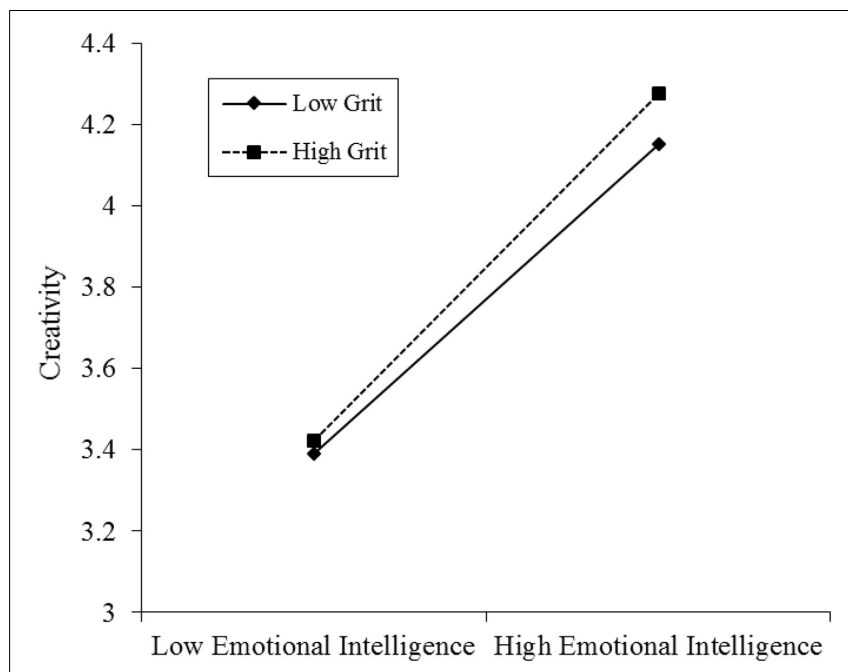

FIGURE 2 | The moderated effect of grit on emotional intelligence and individual creativity.

(Duan et al., 2013). And good emotional intelligence ability can make the individual perceive more positive emotions and have a beneficial impact on the individual's creativity. Attachment theory suggests that the parent-child relationship can affect the individual's ability to perceive emotions (Joseph and Newman, 2010). So emotional intelligence is closely related to the family relationship (the parent-child relationship). Therefore, the parent-child relationship can improve individuals' level of emotional intelligence and further improve their level of creativity. Theories related to attachment and emotion provide the theoretical basis for emotional intelligence acting as an intermediary between the parent-child relationship and individual creativity. Second, emotional intelligence in empirical terms can reinforce positive behaviors such as individual performance (O'Boyle et al., 2011), innovative behavior (Wang et al., 2016), and job involvement (Yan et al., 2018). Moreover, the parent-child relationship can improve the level of emotional intelligence (Belean and Năstasă, 2017; Wang et al., 2019). Hence, this study in both theoretical and empirical terms verifies that emotional intelligence plays a mediating role in the relationship between the parent-child relationship and individual creativity.

\section{The Moderating Effects of Grit}

This study found that grit played a moderating role in the relationship between the parent-child relationship and individual creativity. To be specific: the moderating effects occur at the second half of the mediating chain. In other words, grit has regulated the relationship between emotional intelligence and individual creativity. Results show that grit can significantly improve emotional intelligence's impact on individual creativity, however, low its level is. According to "protective factorprotective factor" (Cohen et al., 2003), two kinds of protective factors have different effects on individual creativity: the facilitating effect and the excluding effect. However, this study found that grit had an accumulative effect rather than a reductive effect on emotional intelligence, which indicates that grit can help individuals find new solutions and further improve their creativity through interest and unremitting efforts.

\section{Research Limitations and Future Research}

There are some valuable conclusions in this study, but it has its limitations. Firstly, in our sample, over-represent women and under-represent older students, and besides gender and age, we do not collect other demographic characteristics. The study in the future can increase the sample size of man and collect more demographic characteristics to enhance the sample's representativeness. Meanwhile, in the future, it may be necessary to randomly select students from vocational colleges across the country as subjects for research to be more representative. Secondly, this study fails to find the exact causal relationship between variables by using a multi-time data collection design. The study in the future may use longitudinal cross-lag studies experimental designs to explore the exact causal relationship between the variables. Third, although this study has used statistical control in data processing, errors are unavoidable. The study in the future may use the experimental method and the evaluation method to control errors from the source. 
Fourth, the limited evidence of the validity of the measurement scales for this study, although the authors calculated values of Cronbach's alpha and performed confirmatory analyses, there was no other evidence of validity. Meanwhile, we use only single overall scores from each survey instrument, and we do not explore the role of each dimension in detail, although this allow us to get some conclusions, it also limits the depth of this research. The study in the future may need to provide additional validity evidence for research tools, for example, conduct cognitive interviews to check that the students interpreted the survey items as intended. In addition, the study in the future can conduct a detailed analysis of the role of each dimension to draw broader conclusions. Finally, the parent-child relationship is not the only antecedent variable for individual creativity. The study in the future may explore the antecedent variables and mechanisms of creativity from multiple perspectives so as to lay the foundation for cultivating individual creativity.

\section{DATA AVAILABILITY STATEMENT}

The raw data supporting the conclusions of this article will be made available by the authors, without undue reservation.

\section{REFERENCES}

An, J. S., and Cooney, T. M. (2006). Psychological well-being in mid to late life: the role of generativity development and parent-child relationships across the lifespan. Int. J. Behav. Dev. 30, 410-421. doi: 10.1177/016502540607 1489

Avis, J., and Orr, K. (2016). HE in FE: vocationalism, class and social justice. Res. Post-Compul. Educ. 21, 49-65. doi: 10.1080/13596748.2015.112 5666

Belean, R. D., and Năstasă, L. E. (2017). The relationship between parental style, parental competence and emotional intelligence. Bull. Trans. Univ. Brasov Ser. VII Soc. Sci. Law 10, 181-190.

Bowlby, E. J. M. (2010). Separation: Anxiety and Anger: Attachment and Loss. New York, NY: Random House.

Brackett, M. A., Rivers, S. E., and Salovey, P. (2011). Emotional intelligence: implications for personal, social, academic, and workplace success. Soc. Pers. Psychol. Compass 5, 88-103. doi: 10.1111/j.1751-9004.2010.00334.x

Bronfenbrenner, U. (1989). "Ecological systems theory," in Six Theories of Child Development: Revised Formulations and Current Issues, ed. R. Vasta (Greenwich, CT: JAI Press), 187-249.

Brook, J. S., Brook, D. W., Ning, Y., Whiteman, M., and Finch, S. J. (2006). The relationship of personality and behavioral development from adolescence to young adulthood and subsequent parenting behavior. Psychol. Rep. 99, 3-19. doi: $10.2466 /$ pro.99.1.3-19

Bruce, P. A. (2014). Forgiveness as a Mediator Between Emotional Intelligence and Parent-Child Relationships. Doctoral dissertation. San Diego, CA: Northcentral University.

Cohen, J., Cohen, P., West, S. G., and Aiken, L. S. (2003). Applied Multiple Regression/Correlation Analysis for the Behavioral Sciences, 3rd Edn. Mahwah, NJ: Lawrence Erlbaum Associates, Inc.

Côté, S. (2014). Emotional intelligence in organizations. Annu. Rev. Organ. Psychol. Organ. Behav. 1, 459-488.

Csikszentmihalyi, M. (1999). "Implications of a systems perspective for the study of creativity," in Handbook of Creativity, ed. R. J. Sternberg (Cambridge: Cambridge University Press), 313-335.

Duan, J., Tian, X., and Wang, X. (2013). The influence of emotional intelligence on employee creativity. Sci. Res. Manage. 34, 106-114. doi: 10.1146/annurevorgpsych-031413-091233

\section{ETHICS STATEMENT}

This study was carried out in accordance with academic ethics guidelines, and the recommendations of the Committee of History-cultural and Tourism School of Gannan Normal University, which also approved the study protocol. All subjects provided written informed consent in accordance with the Declaration of Helsinki.

\section{AUTHOR CONTRIBUTIONS}

YsW: conceptualization. DC: investigation and data curation. YsW and DC: methodology and writing original draft. YsW, WZ, and YbW: writing - review and editing. All authors contributed to the article and approved the submitted version.

\section{FUNDING}

This research was funded by the China Social Science Fund Youth Project (No. 21CSH076) and projects funded by bidding for key research bases in Jiangxi Province, China (JD17011).

Duckworth, A. L., Peterson, C., Matthews, M. D., and Kelly, D. R. (2007). Grit: perseverance and passion for long-term goals. J. Pers. Soc. Psychol. 92, 10871101. doi: 10.1037/0022-3514.92.6.1087

Faul, F., Erdfelder, E., Buchner, A., and Lang, A. G. (2009). Statistical power analyses using $\mathrm{G}^{*}$ Power 3.1: tests for correlation and regression analyses. Behav. Res. Methods 41, 1149-1160. doi: 10.3758/BRM.41.4.1149

Fredrickson, B. L. (2001). The role of positive emotions in positive psychology: the broaden-and-build theory of positive emotions. Am. Psychol. 56, 218-226. doi: 10.1037/0003-066x.56.3.218

Gale, T., and Tranter, D. (2011). Social justice in Australian higher education policy: an historical and conceptual account of student participation. Crit. Stud. Educ. 52, 29-46. doi: 10.1080/17508487.2011.536511

Garmezy, N., Masten, A. S., and Tellegen, A. (1984). The study of stress and competence in children: a building block for developmental psychopathology. Child Dev. 55, 97-111. doi: 10.2307/1129837

Griffioen, D., and de Jong, U. (2013). Academic drift in Dutch non-university higher education evaluated: a staff perspective. Higher Educ. Policy 26, 173-191. doi: $10.1057 /$ hep. 2012.24

Joseph, D. L., and Newman, D. A. (2010). Emotional intelligence: an integrative meta-analysis and cascading model. J. Appl. Psychol. 95, 54-78. doi: 10.1037/ a0017286

Lei, T., Jiang, K., and Qiao, H. (2019). The relationship between social rejection and school adaptation in migrant children: the moderating effect of grit. Chin. J. Special Educ. 11, 69-74.

Li, J., and Shi, J. (2004). Childrens creativity development and the effect of family environment. Acta Psychol. Sin. 36, 732-737. doi: 10.1007/BF02911031

Neufeld, J. E., Rasmussen, H. N., Lopez, S. J., Ryder, J. A., Magyar-Moe, J. L., Ford, A. I., et al. (2006). The engagement model of person-environment interaction. Counsel. Psychol. 34, 245-259. doi: 10.1177/0011000005281319

O’Neal, C. R., Espino, M. M., Goldthrite, A., Morin, M. F., Weston, L., Hernandez, P., et al. (2016). Grit under duress: stress, strengths, and academic success among non-citizen and citizen Latina/o first-generation college students. Hispanic J. Behav. Sci. 38, 446-466. doi: 10.1177/0739986316660775

O’Boyle, E. H. Jr., Humphrey, R. H., Pollack, J. M., Hawver, T. H., and Story, P. A. (2011). The relation between emotional intelligence and job performance: a meta-analysis. J. Organ. Behav. 32, 788-818. doi: 10.1002/job.714

Olson, D. H., Sprenkle, D. H., and Russell, C. S. (1979). Circumplex model of marital and family systems: I. Cohesion and adaptability dimensions, family 
types, and clinical applications. Fam. Process 18, 3-28. doi: 10.1111/j.1545-5300. 1979.00003.x

Padilla-Walker, L. M., Nielson, M. G., and Day, R. D. (2016). The role of parental warmth and hostility on adolescents' prosocial behavior toward multiple targets. J. Fam. Psychol. 30, 331-340. doi: 10.1037/fam0000157

Parry, G. (2009). Higher education, further education and the english experiment. Higher Educ. Q. 63, 322-342. doi: 10.1111/j.1468-2273.2009.00443.x

Podsakoff, P. M., Mackenzie, S. B., Lee, J. Y., and Podsakoff, N. P. (2003). Common method biases in behavioral research: a critical review of the literature and recommended remedies. J. Appl. Psychol. 88, 879-903. doi: 10.1037/0021-9010. 88.5.879

Preacher, K. J., and Hayes, A. F. (2004). SPSS and SAS procedures for estimating indirect effects in simple mediation models. Behav. Res. Methods Instruments Comp. 36, 717-731. doi: 10.3758/BF03206553

Preacher, K. J., Rucker, D. D., and Hayes, A. F. (2007). Addressing moderated mediation hypotheses: theory, methods, and prescriptions. Multiv. Behav. Res. 42, 185-227. doi: 10.1080/00273170701341316

Rodrigues, A. P., Jorge, F. E., Pires, C. A., and António, P. (2019). The contribution of emotional intelligence and spirituality in understanding creativity and entrepreneurial intention of higher education students. Educ. Train. 61, 870894. doi: 10.1108/ET-01-2018-0026

Runco, M. A. (2007). A hierarchical framework for the study of creativity. New Horizons Educ. 55, 1-9.

Sen, S., Acar, S., and Cetinkaya, C. (2014). Development of the personenvironment fit scale (pefsc): a new measure of creativity. Psychol. Aesthet. Creat. Arts 8, 433-445. doi: 10.1037/a0037724

Wang, G., Sun, W., Zheng, Q., and Zhao, S. (2016). The effect of emotional creativity on employees' innovative behavior: social constructivist view of emotion perspective. J. Psychol. Sci. 39, 124-130.

Wang, Y., Li, Z., and Zhu, L. (2019). Emotional intelligence of 3- to 6-year-olds and parenting style: peer communication ability as a mediator. Soc. Behav. Pers. Int. J. 47, 1-12.

Warren, F., Mason-Apps, E., Hoskins, S., Azmi, Z., and Boyce, J. (2018). The role of implicit theories, age, and gender in the creative performance of children and adults. Think. Skills Creat. 28, 98-109. doi: 10.1016/j.tsc.2018.03.010

Wen, Z., and Baojuan, Y. E. (2014). Different methods for testing moderated mediation models: competitors or backups? Acta Psychol. Sin. 46, 714-726. doi: 10.3724/SP.J.1041.2014.00714
Wong, C. S., and Law, K. S. (2002). The effects of leader and follower emotional intelligence on performance and attitude: an exploratory study. Leadership Q. 13, 243-274. doi: 10.1016/S1048-9843(02)00099-1

Xue, E., and Li, J. (2021). Exploring the type-based vocational education system: insights from China. Educ. Philos. Theory 1-11. doi: 10.1080/00131857.2021. 1934668

Yan, X., Yang, K., Su, J., Luo, Z., and Wen, Z. (2018). Mediating role of emotional intelligence on the associations between core self-evaluations and job satisfaction, work engagement as indices of work-related well-being. Curr. Psychol. 37, 552-558. doi: 10.1007/s12144-016-9531-2

Zhang, D., Zhou, Z., Gu, C., Lei, Y., and Fan, C. (2018). Family socio-economic status and parent-child relationships are associated with the social creativity of elementary school children: the mediating role of personality traits. J. Child Fam. Stud. 27, 2999-3007. doi: 10.1007/s10826-018-1130-4

Zhang, W. J., Ren, P., and Deng, L. (2018). Gender differences in the creativityacademic achievement relationship: a study from china. J. Creat. Behav. 54, 725-753. doi: 10.1002/jocb.387

Zhang, W., Wang, M., and Fuligni, A. (2006). Expectations for autonomy,beliefs about parental authority, and parent-adolescent conflict and cohesion. Acta Psychol. Sin. 38, 868-876. doi: 10.1016/S0379-4172(06)6 0092-9

Conflict of Interest: The authors declare that the research was conducted in the absence of any commercial or financial relationships that could be construed as a potential conflict of interest.

Publisher's Note: All claims expressed in this article are solely those of the authors and do not necessarily represent those of their affiliated organizations, or those of the publisher, the editors and the reviewers. Any product that may be evaluated in this article, or claim that may be made by its manufacturer, is not guaranteed or endorsed by the publisher.

Copyright (c) $2021 \mathrm{Wu}, \mathrm{Wu}$, Chong and Zhang. This is an open-access article distributed under the terms of the Creative Commons Attribution License (CC BY). The use, distribution or reproduction in other forums is permitted, provided the original author(s) and the copyright owner(s) are credited and that the original publication in this journal is cited, in accordance with accepted academic practice. No use, distribution or reproduction is permitted which does not comply with these terms. 